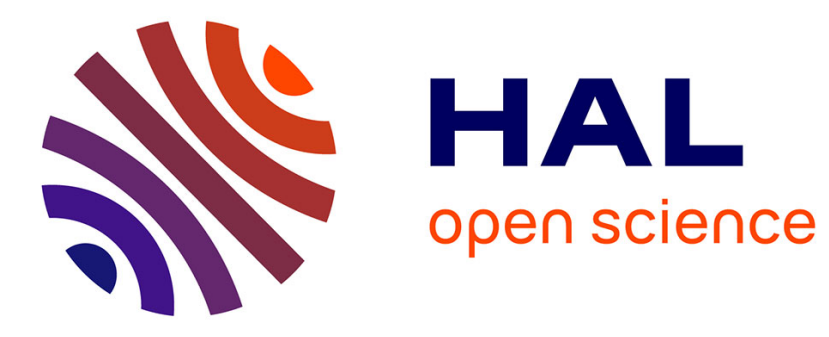

\title{
Chikungunya Infection in Hospitalized Febrile Infants Younger Than 3 Months of Age.
}

Narcisse Elenga, Marion Folin, Yves-Marie Vandamme, Emma

Cuadro-Alvarez, Laurence Long, Falucar Njuieyon, Elise Martin, Rémi

Kom-Tchameni, Antoine Defo, Sitraka Herinantenaina Razafindrakoto, et al.

\section{To cite this version:}

Narcisse Elenga, Marion Folin, Yves-Marie Vandamme, Emma Cuadro-Alvarez, Laurence Long, et al.. Chikungunya Infection in Hospitalized Febrile Infants Younger Than 3 Months of Age.. Pediatric Infectious Disease Journal, 2017, Epub ahead of print. 10.1097/INF.0000000000001541 . inserm01476019

\section{HAL Id: inserm-01476019 https://www.hal.inserm.fr/inserm-01476019}

Submitted on 24 Feb 2017

HAL is a multi-disciplinary open access archive for the deposit and dissemination of scientific research documents, whether they are published or not. The documents may come from teaching and research institutions in France or abroad, or from public or private research centers.
L'archive ouverte pluridisciplinaire HAL, est destinée au dépôt et à la diffusion de documents scientifiques de niveau recherche, publiés ou non, émanant des établissements d'enseignement et de recherche français ou étrangers, des laboratoires publics ou privés. 
The Pediatric Infectious Disease Journal Publish Ahead of Print

DOI: 10.1097/INF.0000000000001541

Chikungunya Infection in Hospitalized Febrile Infants Younger Than 3 Months of Age Narcisse Elenga, ${ }^{1}$ MD, PhD, Marion Folin, ${ }^{1}$ MD, Yves-Marie Vandamme ${ }^{2}$, MD, Emma Cuadro-Alvarez, ${ }^{1}$ MD, Laurence Long, ${ }^{1}$ MD, Falucar Njuieyon, ${ }^{1}$ MD, Elise Martin, ${ }^{1}$ MD, Rémi Kom-Tchameni, ${ }^{1}$ MD, Antoine Defo, ${ }^{1}$ MD, Sitraka Herinantenaina Razafindrakoto, ${ }^{1} \mathrm{MD}$, Yajaira Mrsic, ${ }^{1} \mathrm{MD}$, Pierre Couppie, ${ }^{3} \mathrm{MD}$, PhD, Mathieu Nacher, ${ }^{4}$ MD, PhD, and Julie Dufour, ${ }^{3} \mathrm{MD}$

${ }^{1}$ Pediatric Medicine and Surgery, Cayenne Hospital, Rue des flamboyants, BP 6006, 97306

Cayenne Cedex, French Guiana

${ }^{2}$ Department of Infectious Disease, University Hospital of Angers, France

${ }^{3}$ Department of Dermatology, Cayenne Hospital, Rue des flamboyants, BP 6006, 97306 Cayenne

Cedex, French Guiana

${ }^{4}$ Centre d'Investigation Clinique Antilles-Guyane, Cayenne Hospital, Rue des flamboyants, BP 6006, 97306 Cayenne Cedex, French Guiana

Corresponding author: Narcisse Elenga

Dept of Pediatrics, Regional Hospital, Cayenne, French Guiana

Rue des Flamboyants BP 6006-97306 Cayenne Cedex

Tel.(+594)694978048, e.mail:elengafr@yahoo.fr

Abbreviated title: Chikungunya Infection in Infants

Running head: Chikungunya Infection

Key words: Chikungunya virus, fever-irritability-elevated procalcitonin, infants, French Guiana

Sources of support: None

The authors have no conflicts of interest or funding to disclose. 
Background: Fever in infants younger than 3 months is generally a cause for concern because of the risk for a serious bacterial infection. The aim of this study was to describe clinical and biological features of Chikungunya infection in infants $<3$ months of age hospitalized in Cayenne Hospital during the 2014-2015 outbreak.

Methods: We performed a preliminary retrospective study followed by a prospective study from March 2014 to February 2015. All infants younger than 3 months presenting with fever and hospitalized in Cayenne Hospital were included. The main diagnostic criteria were fever and positive Chikungunya PCR.

Results: One hundred and twenty infants were hospitalized with fever. The mean age was 46 days ( $\mathrm{SD} \pm 22$ days). The mean hospitalization duration was 7.4 days ( $\mathrm{SD} \pm 6.1$ days). Chikungunya infection was diagnosed in 26 children. The most important clinical findings were high (80.8\% [77.5-84]) and prolonged fever (76.9\%, [73.4-80.4]), irritability (96.2\% [94.5-97.7]) and skin rash. (69.2\%, [65.4-73]). Half of the infants presented edema of the extremities (hands and feet principally). However, in $15 \%$, Chikungunya infection was associated with a serious bacterial infection. Infants who presented with irritability, high fever and elevated PCT were at high risk for Chikungunya: OR 39, [9.2-243] ( $<<0.001$ ), with a specificity of $96.7 \%$ and a negative predictive value of $89.4 \%$. The area of the ROC curve was 0.96 .

Conclusions: Our results confirm that Chikunguyna infection is a cause of high fever in infants younger than 3 months. Our data should be confirmed by larger studies.

Key words: Chikungunya virus, clinical triad fever-irritability-elevated procalcitonin, infants, French Guiana. 


\section{Introduction}

From July 2014 to April 2015, French Guiana, the biggest French overseas territory in South America was affected by a Chikungunya outbreak. This re-emerging arbovirus infection continues to increase because of non-immune populations, migrant populations, the adaptability of the virus, and possibly global warming increasing the number of potential vectors (1). The first cases of this tropical viral disease were reported in Tanzania in 1952 and gradually spread into Asia (India in particular). The re-emergence of the virus was marked by an intial epidemic in the Indian Ocean region. This outbreak appears to have followed a mutation in the viral genome allowing the virus to adapt to Aedes albopictus, which is considered an accessory vector. This mutation occurred simultaneously in several geographically distinct areas and was not limited to a distribution from a single mutant home (2). This mosquito had been identified in Europe in 1979 and its presence was responsible for the first European epidemic in southern Italy in 2006. The first French cases were reported during the great epidemic of 2005 on the island of Reunion where nearly a third of the population was infected. From there, the epidemic continued to increase: in 2010, there was the first metropolitan indigenous case in Southern France. In 2011, the French West Indies were affected, but it was not until July 2014 that the epidemic was officially declared in French Guiana. Given our experience of dengue epidemics (3), and to prevent severe complications, a proactive Chikungunya program was set up at the Emergency Department and the Infectious Diseases and Pediatrics Departments. Patients suspected of having Chikungunya went through a special process with physicians collecting standardized information, systematically rehydrating patients intravenously and hospitalizing those who had more severe illness or were from remote areas and unlikely to return for follow up. 
From mid-December 2014 to April 2015, 3,753 proven cases were reported in French Guiana, including 229 hospitalized cases. 14,460 potential cases were reported in general practice and in the health centers, which were regarded as sentinel networks. In the laboratory of Cayenne Hospital, there were 1,582 positive PCR results during the study period. After April 2015, the number of new cases globally decreased.

The clinical profile of Chikungunya infection in children has been well documented (4-8). After 5 to 8 days of incubation, children present with very high and poorly tolerated fever and often with a skin rash. Polyarthralgia is more moderate in infants than in adults (9), but some serious neonatal forms exist (10-13). Bullous skin rashes and encephalopathy have also been described $(14,15)$. Usually, infants less than 3 months are considered at risk for severe forms of Chikungunya infection as are newborns, the elderly and persons with weakened immune systems. In this study we aimed to investigate the incidence of severe forms of Chikungunya infection in young infants and to identify features that could allow differentiation from other causes of fever.

\section{Methods}

The study was carried out in Cayenne Hospital from March $1^{\text {st, }} 2014$ to February $28^{\text {th }}, 2015$. It was a descriptive, monocentric study.

All infants younger than 90 days hospitalized for fever were included. We excluded infants who had a fever only the waning of hospitalization (it essentially was the premature newborns hospitalized in the neonatal unit)

The data collection was retrospective from March 1st until December $31^{\text {st }}$ and prospective afterwards until the end of the study. Data was entered from computerized hospital records, or 
paper records when computer data was not available. We collected demographic data (age in days, sex, and hospitalization duration), clinical data (fever duration, past medical history, clinical symptomatology such as diarrhea, irritability, poor general condition, skin rash, edema of the extremities, hypotonia.... ), biologic data (absolute neutrophil count, CRP, PCT, urinalysis, lumbar puncture, stool viral and bacterial analysis, malaria smear, Chikungunya PCR, VRS, influenza, search for Pneumococcus in blood hemoculture and cerebrospinal fluid...) and therapeutic data (type of antibiotherapy, dosage and re-evaluation).

All data was collected after informed consent from the legal responsible and was subsequently anonymized.

The main criterion outcome was the positive Chikungunya PCR. The analysis proceeded as follows:

- Description of clinical and biologic data in Chikungunya virus infection.

- Comparison between SBI children and children infected with Chikungunya virus regarding the following variables: sex, age, hospitalization duration, fever $\geq 39^{\circ}$ and $\geq$ 48h, poor general condition, irritability, skin rash eruption, digestive symptomatology, hypotonia, and biological criteria (CRP, PCT, absolute neutrophil count). Subsequently, we compared the Chikungunya group with the group of Non-Chikungunya infected infants, in order to identify the particularities of Chikungunya infection in our study population. 


\section{Definitions}

The fever was defined by a rectal temperature up to $100,4^{\circ} \mathrm{F}\left(38^{\circ} \mathrm{C}\right)$.

The high fever was defined by a rectal temperature up to $102^{\circ} \mathrm{F}\left(39^{\circ} \mathrm{C}\right)$.

We defined irritability as an excessive, inconsolable crying despite attempts to comfort and console by the mother or the caregiver.

The poor general condition associated fever, lethargy and poor feeding.

\section{Biologic methods}

Here, CHIK infection was confirmed by real-time polymerase chain reaction. RealStar® Chikungunya RT-PCR Kit 2.0 (Altona Diagnostics) was used in $2 \mathrm{ml}$ whole blood samples collected from children with $\leq 5$ days of fever. PCR results were available in 1-2 days. Specimen for PCR were exactly similar to those for virus isolation, with a $100 \%$ sensitivity and specificity $(16,17)$.

\section{Ethical and regulatory aspects}

The data collection was part of the Chikungunya emergency plan and was mandated by the regional health authorities. The anonymized monocentric data issued from medical records was analyzed, which was authorized according to the Regulatory authorities (Commission Nationale Informatique et Libertés number TFN1490159N).

\section{Data analysis}

Data analysis was performed using Stata 13. Quantitative variables were categorized according to statistical criteria using the first and third quartiles and the median. Single comparisons were performed with T-student test for qualitative data and Exact Fisher test for quantitative data. All p-values $<0.25$ were included in the multivariate of logistic regression model. We expressed results means, odds ratios and confidence intervals. The P-values $<0.05$ were considered 
statistically significant. The final model included variables that were significantly associated with the failure event in a single covariable analysis.

\section{Results}

From, March 1, 2014 to February $28^{\text {th }}, 2015,719$ children younger than 3 months attended Cayenne Hospital emergency department (Fig. 1).). One hundred and twenty children with fever (16.7\%) were hospitalized: there were 67 girls and 53 boys (sex ratio: 1.3). The mean age was 46 days ( \pm 22 days). The mean hospitalization duration was 7.4 days $( \pm 6.1$ days $)$. We did not have any cases of malaria or dengue fever in our study population.

Chikungunya infection was diagnosed in 26 children. In 11 cases $(42.3 \%)$, there was a simultaneous familial infection linked to the infant's diagnosis. In 4 cases $(15.4 \%)$, there was a simultaneous infection in neighbors linked to the infant's diagnosis.

The most important symptomatology was high (80.8\% [77.5-84]) and prolonged fever (>7 days) (76.9\% [73.4-80.4]), irritability (96.2\% [94.5-97.7]) and skin rash. (69.2\% [65.4-73]). Poor general condition with anorexia was found in $84.6 \%$ of cases [81.6-87.6]. Half of the infants presented edematous extremities (hands and feet principally). One third of infants presented vesiculobullous exanthem (Fig 2\&3). However, in 15\% of cases, Chikungunya infection was associated with a SBI (Fig. 1). Biologically, there was a moderate hepatic cytolysis in $84.6 \%$ [81.6-87.6] of the cases. Some patients had cholestasis, moderate transitory lymphopenia and neutropenia. Rare cases of coagulation diseases were found but prothrombin was always higher than $50 \%$ and platelets always up to $80.000 \mathrm{G} / \mathrm{L}$. Chikungunya cases are described in tables 1 and 2. Infants who presented irritability, high fever and skin rash were more likely to have 
Chikungunya infection: OR 39 [9.2-243] ( $<<0.001)$. The specificity of the model was $96.7 \%$ and the negative predictive value $89.4 \%$ (table 3 )

When we compared the Chikungunya group and the Non-Chikungunya infected infants (table 2), the Chikungunya group were treated with fewer antibiotics and had a shorter hospitalization duration. However, its clinical initial presentation was remarkable, with irritability still significant in multivariate analysis (AOR: $36,[2-683], \mathrm{p}=0.0017$ ).

CRP > 20mg/L was associated with SBI (OR: 0.3 [0.08-0.9], p=0.02) but PCT was associated with Chikungunya infection, OR: 3.6 [1.13-11.9], $\mathrm{p}=0.022$. The $\mathrm{OR}$ is remained significant in multivariate analysis, AOR: 4.9 [1.2-18], $(\mathrm{p}=0.036)$. The Receiver Operating Characteristic (ROC) analysis was used to quantify how accurately our medical diagnostic test (feverirritability-elevated PCT) can discriminate between Chikungunya and Non-Chikungunya infants. In our multivariate model, the area of the ROC curve was 0.96 (Figure 4).

Six children were transferred to the pediatric intensive care unit. The main manifestations were neurological symptoms ( 1 convulsion and 1 bulging fontanelle), dyspnea in 4 cases. No death or relapses were observed.

\section{Discussion}

The clinical presentation of the Chikungunya infection in our study was similar to that described in infants in the literature $(6,13,15)$. Chikungunya infection in very young children was associated with high prolonged, poorly tolerated fever and irritability. This clinical form may be confused with systemic bacterial infection and treated with antibiotics, when in fact; it is a benign viral infection. However, during the 2005-2006 epidemic on Reunion Island, there were 
reports of rare severe forms involving both adults and children $(16,17)$. Nevertheless, we did not observe any severe forms as in the Réunion study (14).

The clinical triad: fever-irritability-elevated PCT was nearly 40 times more representative of Chikungunya infection $(\mathrm{p}<0.001)$. The specificity and the NPV were high, and the area under the ROC curve was close to 1 , confirming the quality of our model in this epidemic context. This triad may be particularly interesting for isolated centers that do not have easy access to blood testing. However, caution is required in the applicability to other contexts where malaria or dengue cases may have mimicked features of Chikungunya (18-20). The vesiculobullous exanthem, lymphopenia (but not neutropenia) were frequent as described in the literature (21). In the literature, low platelet counts and coagulation disorders seemed to be more frequent whereas they concerned barely $8 \%$ of our population $(7,22)$. Liver abnormalities were relatively frequent both in our study and in the literature $(7,22)$.

Chikungunya could be associated with SBI in $15.4 \%$ [12.4-18.3]. Others have shown a higher risk of bacterial co-infection in Chikungunya infected young children (6).

Our results highlighted that CRP was significantly higher in the SBI group than the Chikungunya group. $(\mathrm{p}=0.02)$. However, PCT was in favor of viral Chikungunya infection in univariate $(\mathrm{p}=$ $0.022)$ and multivariate analysis $(\mathrm{p}=0.036)$. Some studies highlighted that PCT was a bacterial marker with a 96.3\% NPV (23-27). However, other studies contradicted this result with no significant association between PCT and SBI $(28,29)$. We had a very low number of patients and our results should be confirmed by larger studies.

In our population, we did not have any complications or re-hospitalizations in the Chikungunya group, but as reported in the literature, mostly encephalopathy and multiorgan failure. $(4,7,8$, $14,15)$. 


\section{References}

1-Morrison TE. Reemergence of Chikungunya virus. J Virol. 2014; 88 (20):11644-7.

2-Pialoux G, Gaüzère BA, Jauréguiberry S, et al. Chikungunya, an epidemic arbovirosis. Lancet Infect Dis. 2007; 7(5):319-27.

3-Djossou F, Vesin G, Walter G, et al. Incidence and predictive factors of transaminase elevation in patients consulting for dengue fever in Cayenne Hospital, French Guiana. Trans R Soc Trop Med Hyg. 2016; 110 (2) :134-40.

4-Gopakumar H, Ramachandran S. Congenital chikungunya. J Clin Neonatol. 2012 ;1(3):155-6.

5-Gérardin P, Barau G, Michault A, et al. Multidisciplinary prospective study of mother-to-child chikungunya virus infections on the island of La Réunion. PLoS Med. 2008; 18 ; 5 (3): e60.

6-Valamparampil JJ, Chirakkarot S, Letha S, et al. Clinical profile of Chikungunya in infants. Indian J Pediatr. 2009;76 (2): 151-5.

7-Le Bomin A, Hebert JC, Marty P, et al. [Confirmed chikungunya in children in Mayotte.

Description of 50 patients hospitalized from February to June 2006]. Médecine Trop Rev Corps Santé Colon. 2008; 68 (5): 491-5.

8-Pinzón-Redondo H, Paternina-Caicedo A, Barrios-Redondo K, et al. Risk Factors for Severity of Chikungunya in Children: A Prospective Assessment. Pediatr Infect Dis J. 2016

9-Rodriguez-Morales AJ, Gil-Restrepo AF, Ramírez-Jaramillo V, et al. Post-chikungunya chronic inflammatory rheumatism: results from a retrospective follow-up study of 283 adult and child cases in La Virginia, Risaralda, Colombia. F1000Res. 2016; 16; 5: 360.

10-Gopakumar H, Ramachandran S. Congenital chikungunya. J Clin Neonatol. 2012 ;1(3):155-6. 
11-Boumahni B, Bintner M. [Five-year outcome of mother-to-child transmission of chikungunya virus]. Med Trop. 2012;72 Spec No:94-6.

12-Gérardin P, Sampériz S, Ramful D, et al. Neurocognitive outcome of children exposed to perinatal mother-to-child Chikungunya virus infection: the CHIMERE cohort study on Reunion Island. PLoS Negl Trop Dis. 2014 ;17; 8(7):e2996.

13-Villamil-Gómez W, Alba-Silvera L, Menco-Ramos A, et al. Congenital Chikungunya Virus Infection in Sincelejo, Colombia: A Case Series. J Trop Pediatr. 2015; 61 (5) :386-92.

14- Pellot AS, Alessandri JL, Robin S, et al. [Severe forms of chikungunya virus infection in pediatric intensive care unit on Reunion Island]. Med Trop. 2012;72 Spec No:88-93.

15-Robin S, Ramful D, Zettor J, et al. Severe bullous skin lesions associated with Chikungunya virus infection in small infants. Eur J Pediatr 2010; 169: 67-72

16-Dash PK, Parida M, Santhosh SR, et al. Development and evaluation of a 1-step duplex reverse transcription polymerase chain reaction for differential diagnosis of chikungunya and dengue infection. Diagn Microbiol Infect Dis 2008;62(1):52-7.

17-Mishra B, Sharma M, Pujhari SK, et al. Utility of multiplex reverse transcriptase-polymerase chain reaction for diagnosis and serotypic characterization of dengue and chikungunya viruses in clinical samples. Diagn Microbiol Infect Dis 2011;71(2):118-25.

18-Soni A, Chugh K, Sachdev A, et al. Management of dengue fever in ICU. Indian J Pediatr. 2001; 68(11): 1051-5.

19- Gérardin P. [Paediatric features of Dengue and Chikungunya fevers]. Arch Pediatr. 2010; 17(1): 86-90.

20-Singhi S, Kissoon N, Bansal A. Dengue and dengue hemorrhagic fever: management issues in an intensive care unit. J Pediatr (Rio J). 2007; 83(2 Suppl): S22-35. 
21- Singh N, Chandrashekar L, Konda D, et al. Vesiculobullous viral exanthem due to chikungunya in an infant. Indian Dermatol Online J. 2014;5, Suppl S2:119-20

22-Ernould S, Walters H, Alessandri J-L, et al. [Chikungunya in paediatrics: epidemic of 20052006 in Saint-Denis, Reunion Island]. Arch Pédiatr. 2008; 15(3): 253-62.

23-Falcão Gonçalves P, Menezes Falcão L, Duque Pinheiro I. Procalcitonin as Biomarker of Infection: Implications for Evaluation and Treatment. Am J Ther. 2015 Mar 23;

24-Al-Zahrani AK, Ghonaim MM, Hussein YM, et al. Evaluation of recent methods versus conventional methods for diagnosis of early-onset neonatal sepsis. J Infect Dev Ctries. 2015; 9(4): 388-93.

25-Qu J, L X, Liu Y, Wang X. Evaluation of procalcitonin, C-reactive protein, interleukin-6 \& serum amyloid A as diagnostic biomarkers of bacterial infection in febrile patients. Indian J Med Res. 2015; 141(3): 315-21.

26-Leli C, Ferranti M, Moretti A, et al. Procalcitonin levels in gram-positive, gram-negative, and fungal bloodstream infections. Dis Markers. 2015; 2015:701480.

27-Mahajan P, Grzybowski M, Chen X, et al. Procalcitonin as a marker of serious bacterial infections in febrile children younger than years old. Acad Emerg Med Off J Soc Acad Emerg Med. 2014; 21(2): 171-9.

28-Díaz MG, García RP, Gamero DB, et al. Lack of Accuracy of Biomarkers and Physical Examination to Detect Bacterial Infection in Febrile Infants. Pediatr Emerg Care. 2015 27;

29-Chang C-H, Tsao K-C, Hu H-C, et al. Procalcitonin and C-reactive protein cannot differentiate bacterial or viral infection in COPD exacerbation requiring emergency department visits. Int J Chron Obstruct Pulmon Dis. 2015; 10:767-74. 


\section{Figure legends}

Fig. 1 Infants younger than 3 months of age consulting in the Emergency Department of Cayenne Hospital (from 03/01/2014 to 02/28/ 2015).

Fig 2. Erythema eruption in an infant with Chikungunya infection

Fig 3. Bullous eruption in an infant with Chikungunya infection

Fig 4. ROC curve testing our multivariate model. The area under the ROC curve was close to 1 , confirming the quality of the model. The ROC analysis is used here to quantify how accurately our medical diagnostic test (fever-irritability-elevated PCT) can discriminate between Chikungunya and Non-Chikungunya infants. 
Table 1: Clinical and biological description of Chikungunya sick patients.

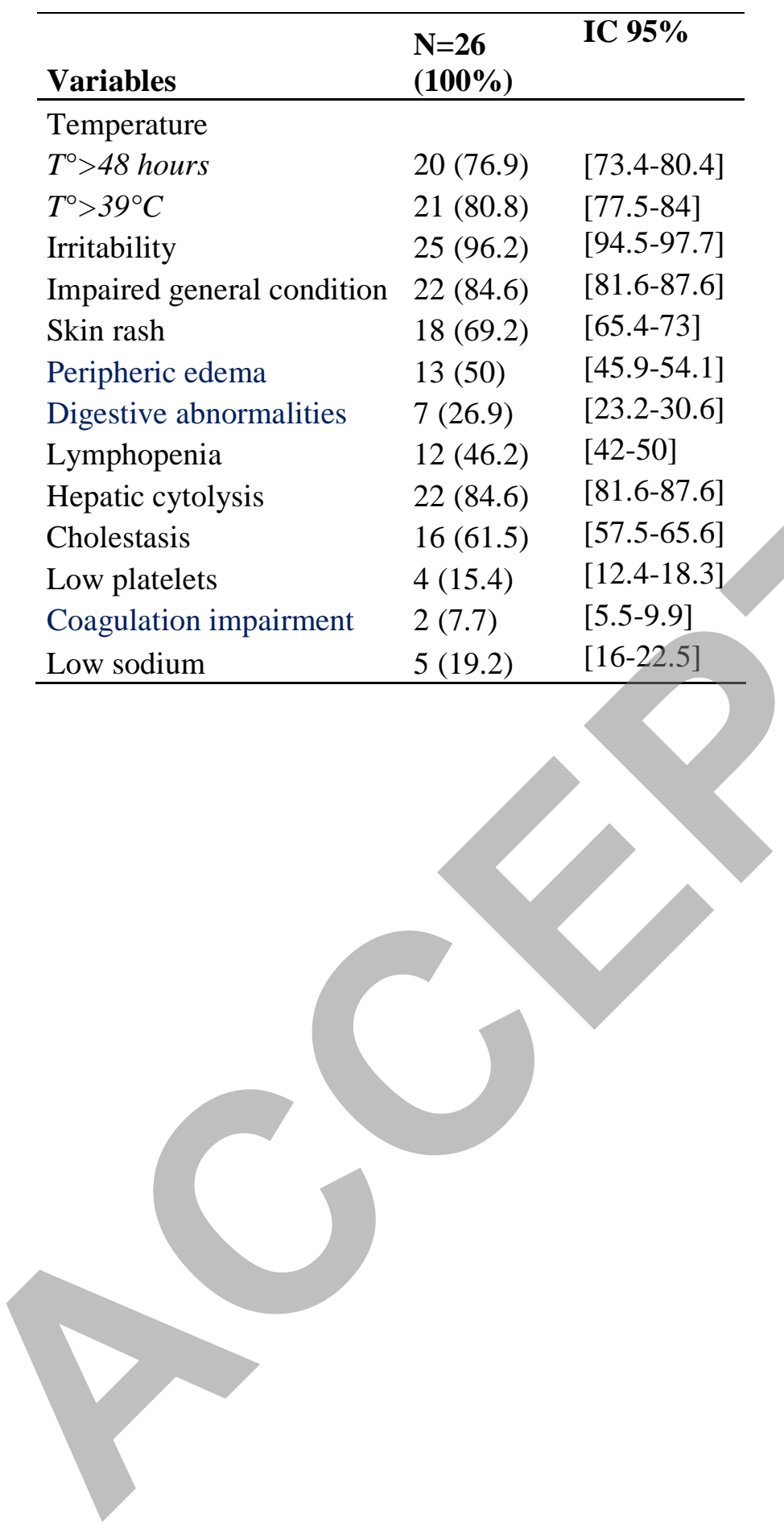


Table 2. Chikungunya sick infants characteristics compared to those without CHIK

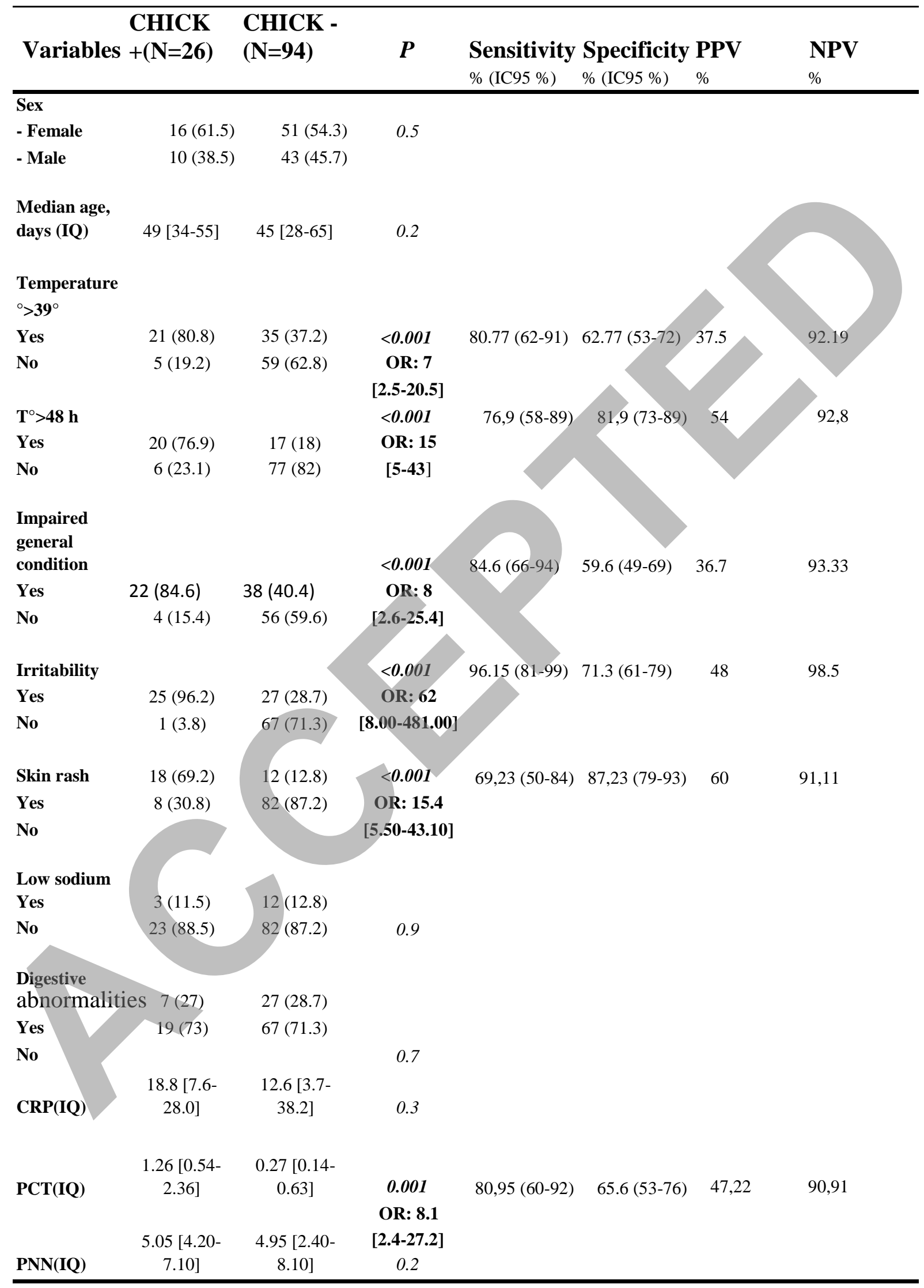


Table 3. Multivariate analysis

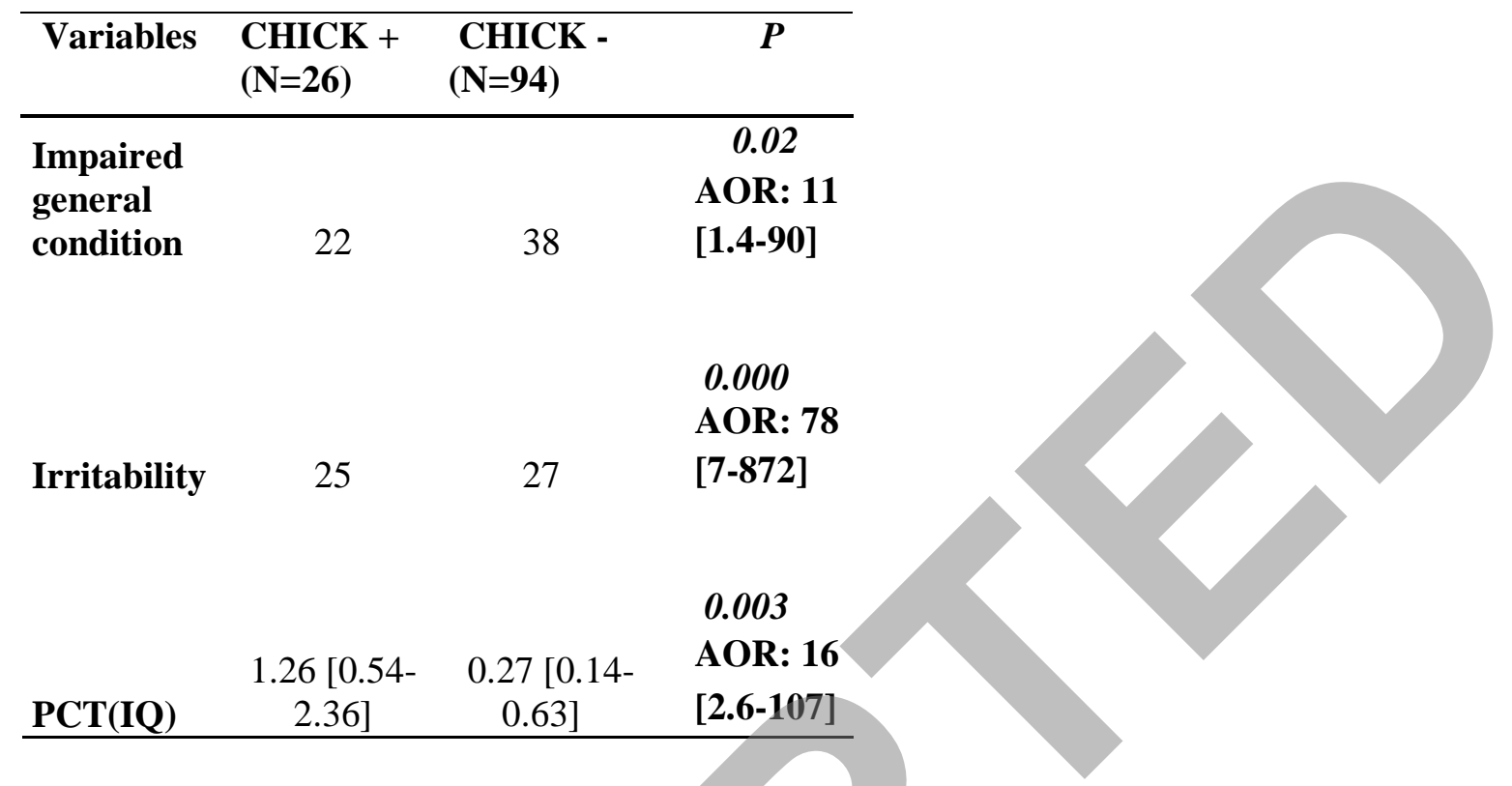

\begin{tabular}{llllll}
\hline Sensitivity & Specificity & PPV & \multicolumn{2}{l}{ NPV } \\
\hline$\%$ & $\%$ & & $\%$ & & $\%$ \\
& 66,7 & 96,7 & 87,5 & 89,4 \\
\hline
\end{tabular}




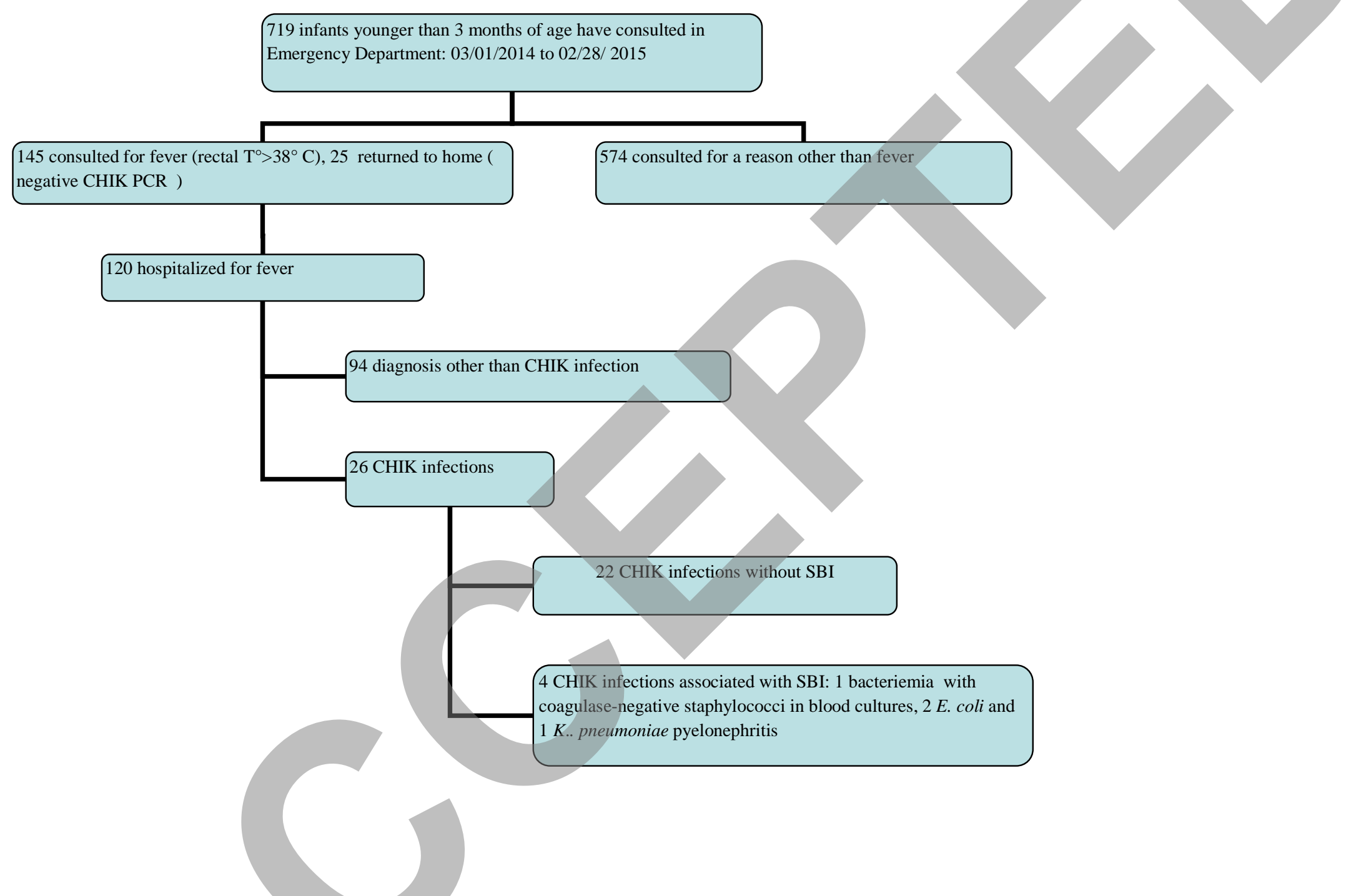

Fig. 1 Infants younger than 3 months of age consulting in the Emergency Department of Cayenne Hospital ( from 03/01/2014 to 02/28/ 2015)

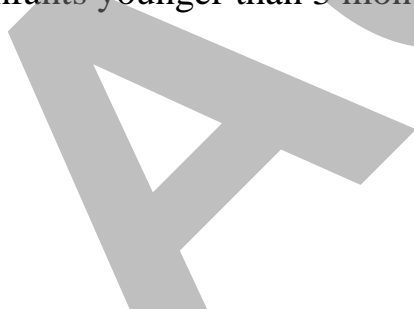




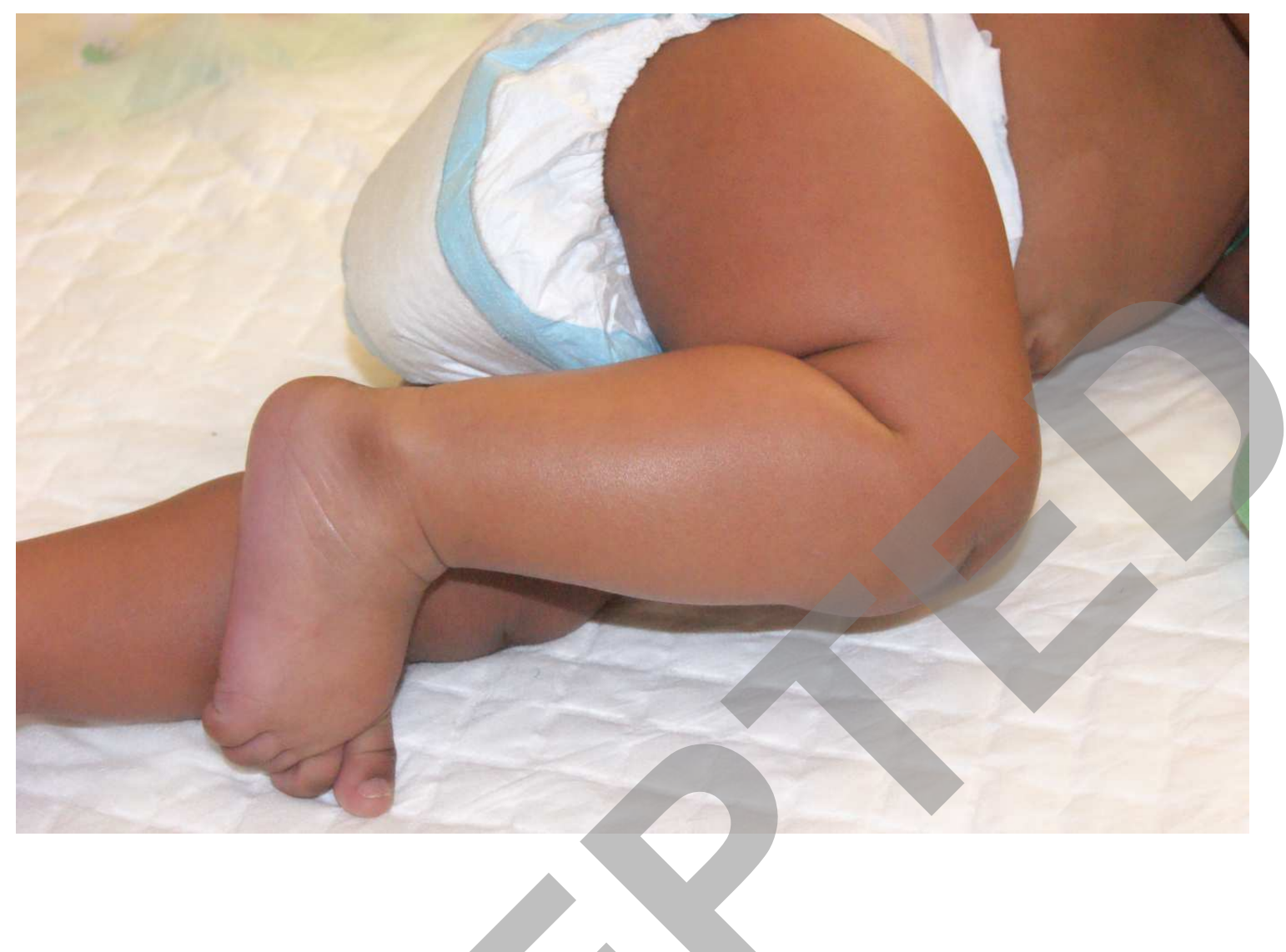

Fig 2. Erythema eruption in an infant with Chikungunya infection

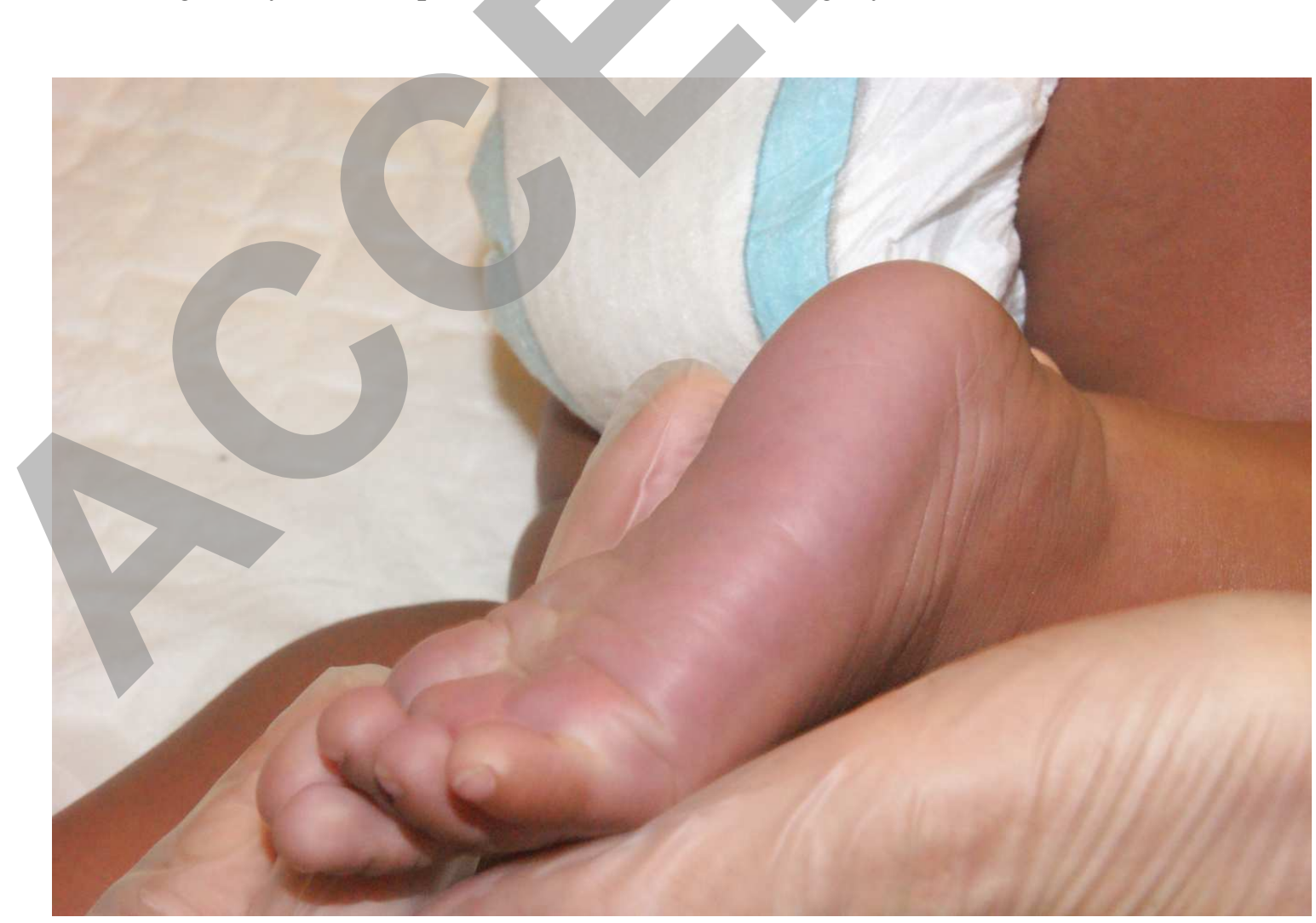

Copyright (c) 2017 Wolters Kluwer Health, Inc. Unauthorized reproduction of this article is prohibited. 


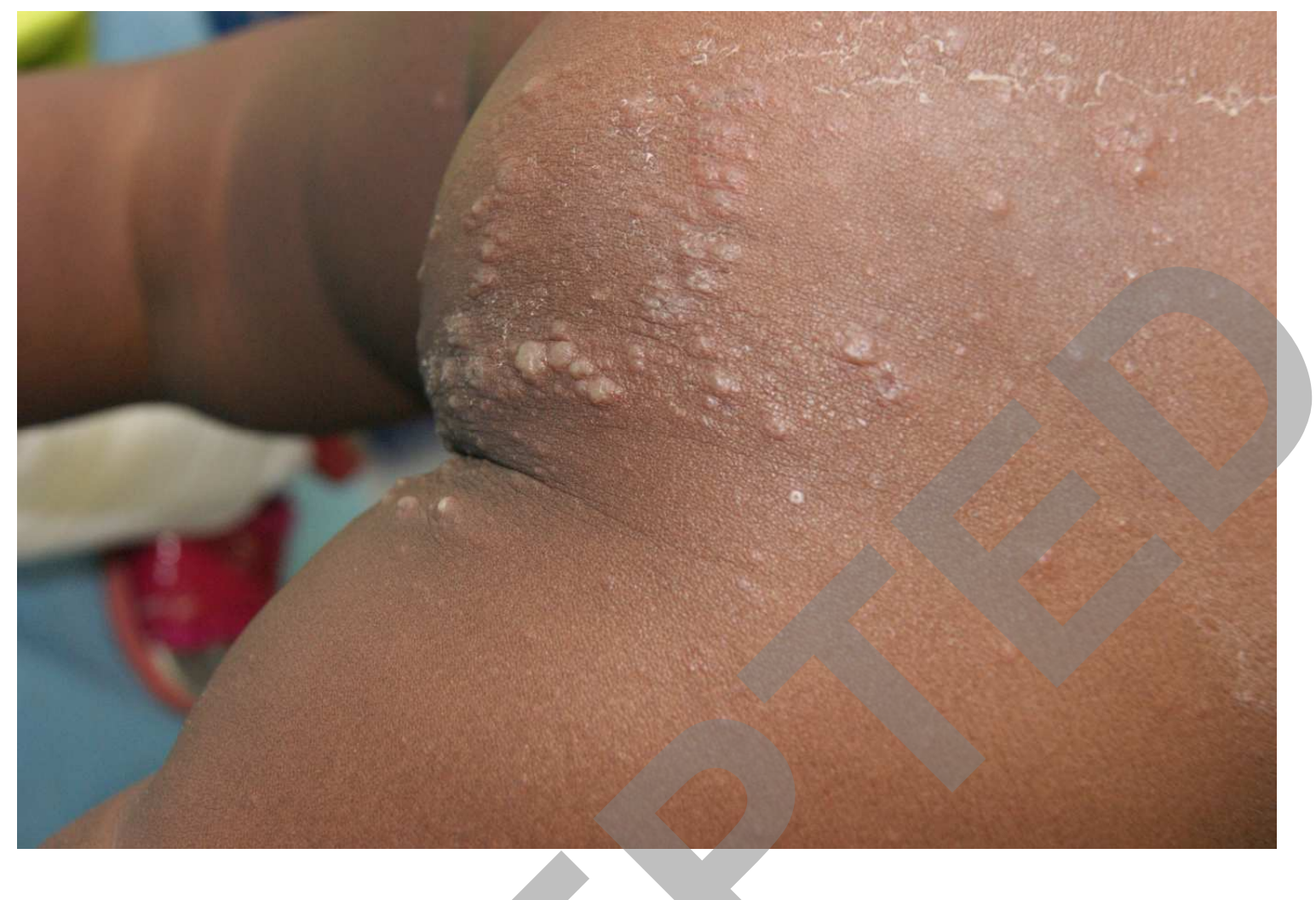

Fig 3. Bullous eruption in an infant with Chikungunya infection 


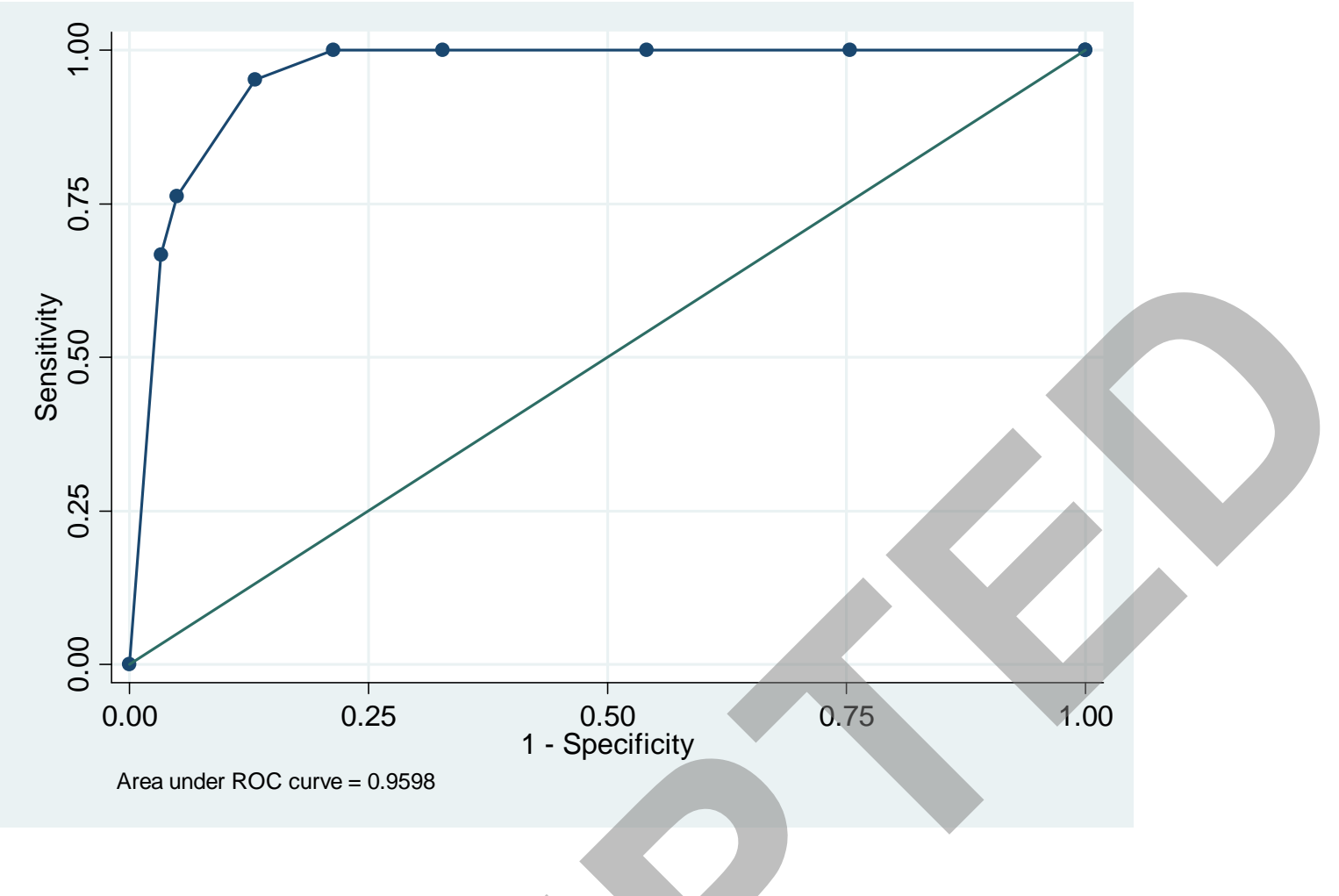

Fig 4. ROC curve testing our multivariate model. The area under the ROC curve was close to 1 , confirming the quality of the model. The ROC analysis is used here to quantify how accurately our medical diagnostic test (fever-irritability-elevated PCT) can discriminate between Chikungunya and Non-Chikungunya infants. 